\title{
Review Article \\ Indoor Decontamination Textiles by Photocatalytic Oxidation: A Review
}

\author{
Hafeezullah Memon, ${ }^{1}$ Sohail Yasin, ${ }^{2}$ Nazakat Ali Khoso, ${ }^{1}$ and Munir Hussain ${ }^{1}$ \\ ${ }^{1}$ Key Laboratory of Advanced Materials and Textiles, Ministry of China, Zhejiang Sci-Tech University, Hangzhou, \\ Zhejiang 310018, China \\ ${ }^{2}$ Lille University of Science and Technology, Cite Scientifique, 59650 Villeneuve-d’Ascq, France
}

Correspondence should be addressed to Hafeezullah Memon; hafeezullah_m@yahoo.com

Received 4 July 2015; Revised 20 October 2015; Accepted 21 October 2015

Academic Editor: Paresh Chandra Ray

Copyright (C) 2015 Hafeezullah Memon et al. This is an open access article distributed under the Creative Commons Attribution License, which permits unrestricted use, distribution, and reproduction in any medium, provided the original work is properly cited.

\begin{abstract}
A large number of researches have been made to make the textile intelligent and smarter; this is achieved by imparting functionality to the textile materials. The indoor environment possesses a variety of pollutants which do not come from the outer environment, but they come from the inner environment itself. Today, the smarter fabrics that may clean the indoor air have been studied by various researchers. The smarter fabrics contain the nanocoating of semiconductor oxides, mostly $\mathrm{TiO}_{2}$; thus the synthesis and application of these nanoparticles on the textile material have been reviewed in this paper. Moreover, there are lots of environmental and health issues regarding nanoparticles that have also been discussed in brief.
\end{abstract}

\section{Introduction}

In general, the term contamination refers to the foreign impurity that is not required and needs to be eliminated. The strategy to remove the contamination from an environment is called decontamination. Decontamination is a broad term and may be considered widely for the removal of different types of contamination from different environments. For the context of this paper, the contamination includes the impurities in the air in the form of gases such as VOCs, odor, smoke, and free aldehydes; these are supposed to be removed from the indoor environment such as offices, halls, and dwellings. Thus the strategy for the removal of abovementioned contaminants from the stated environment is discussed in detail under the title indoor decontamination. The people living in the urban areas suffer much from indoor decontamination [1], as they pass most of their time inside the buildings, and the inner environment of the building possesses a large variety of contaminating items including dusty and continually releasing VOCs such as furniture [2], wall paints, fecal matter of dust mites and bed bugs, printers [3], decorative items [4], cleaning items, wood fire for indoor heating purpose [5], pets, and cigarette smokes [6, 7]. The compressed wood products are used in furniture which use urea-formaldehyde (UF) resin as an adhesive; this can be considered as major indoor contaminating source [2]. Some sources of indoor air contamination have been described in Figure 1.

This suggests the need of removal of contaminants from indoor environment in order to purify it and make it healthier. The removal of contaminants may be done by several ways; some of the common practiced strategies to clean the air inside the buildings are presented in Figure 2. Various researches have been done to clean the inner air of the building by different strategies such as managing temperature and altering surface coolness [8], controlling the humidity [9] of the environment by humidification and dehumidification, circulating the air by exhaust fans, or cleaning the indoor air [10]. Indeed, these methods are temperature dependent and sometimes due to change in temperature they cause even worse environmental conditions. Moreover, they may also cause rise in relative humidity to higher extent, resulting in rise in moist dust in the air. Furthermore, the maintenance cost of all these strategies is an extra surplus making them uneconomical. Approaches have also been made for decontaminating a section without 


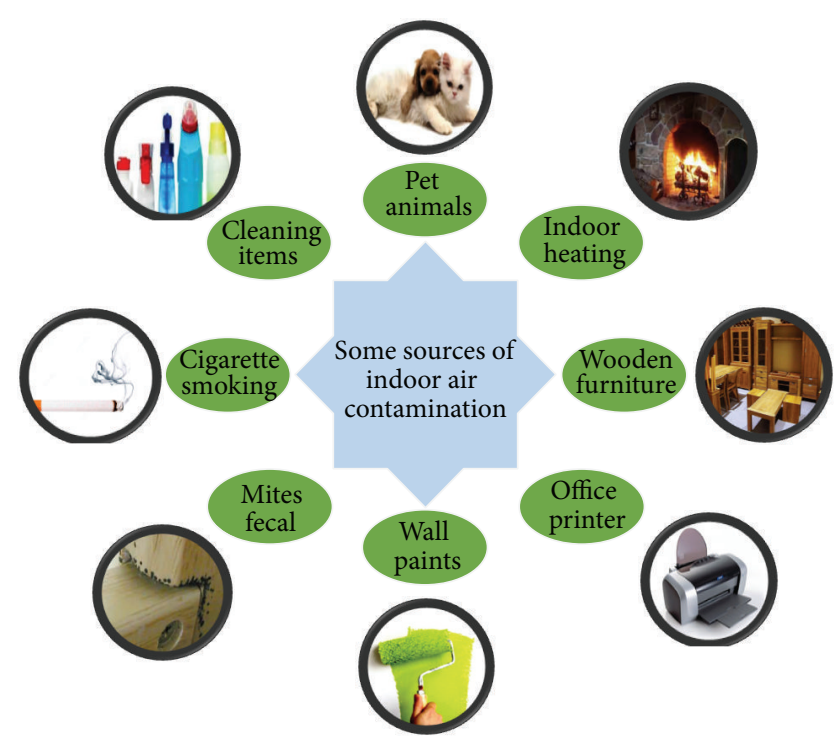

FIgURE 1: Some sources of indoor air contamination.

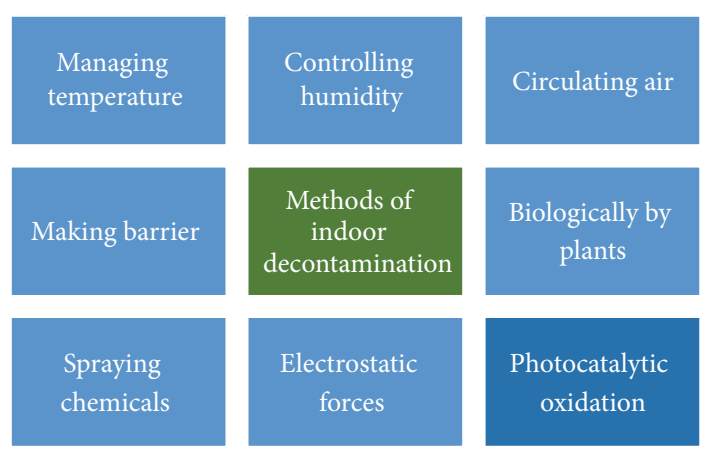

Figure 2: Methods of indoor decontamination.

dehumidification [11]. In addition one strategy that has been practiced to be safe from chemical contamination of the environment is to make barrier against these chemicals [12]; this strategy has been mostly practiced to be safe from hazardous chemicals and thus not user friendly. The activated carbon liners and insulating rubber have been examined to create barrier against hazardous chemical contamination. This strategy is not appreciated because by this the hazardous chemicals remained inside the barrier and later they require being eliminated properly or disposing off of the barrier. The use of various chemicals for the indoor decontamination has also been reported, such as use of hydrogen peroxide [13]. The indoor air may also be cleaned and decontaminated by electrostatic forces, yet the mechanism of ionizing air is only suitable for a bit larger particles in the form of dust around the size of about $0.3 \mu \mathrm{m}$ [14]. The indoor air may also be cleaned by the plants, as some plants possess better decontamination ability for both organic and inorganic compounds [15].

Not only resisting the lethal chemical contamination but also decomposing this deadly chemical contamination into harmless compounds is today's state of the art. Nanotechnology along with the photocatalytic oxidation offers the best possible solution to make better indoor air quality by textile materials. The oxidizing process caused by photocatalysis does not require high temperature making it suitable for textile application and it is chemically and physically stable making it feasible for bulk production. This photocatalytic oxidation has mainly been done by using semiconductor oxides, and many researchers maintain the fact that semiconductor oxides are suitable for degradation of organic compounds and inorganic oxides. Nanotechnology offers two strategies for photocatalytic oxidation either by imparting nanoparticles of semiconductor oxides into spinning solution while spinning of nanofibers or by coating nanoparticles of semiconductor oxides onto the textile substrate.

\section{Indoor Decontamination Textiles}

There is a wide variety made up of textile materials in the indoor environments, for example, the seats, curtains and liners of cars, buses, aeroplanes, trains, ships, and other means of transports, the rugs, sofa covers, wall coverings and curtains of halls, auditoriums, and theatres, and the carpets, table clothes, curtains, bed sheets, and sofa covers of our dwellings. This large variety of textile materials emphasizes the need of changing these traditional textiles into smart textiles, in order to get function from them. Nowadays, people are going to be too much conscious for their health and hygiene. They are demanding the nontoxic, physically and chemically stable, and eco-friendly textile materials; the products that possess all these properties along with an additional benefit of cleaning their environment are highly appreciable. Thus, textile products which are already one of the important parts of our lives may be utilized to protect our environment too. In order to make the indoor decontamination textiles, the conventional textiles may be treated with some functional chemicals or these functional chemicals may be added during the processing of textile material itself. Nonetheless, indoor decontamination textile materials are polymers that do not possess high melting temperatures usually; thus it is necessary that the nanocoating that is going to be applied onto this substrate should possess the synthesis and the application of the nanoparticles at lower temperatures.

Among other methodologies of decontamination pollutants from the textile material, photocatalytic oxidation has more advantages. Moreover, it is also suitable to be applied onto textile materials whether by manufacturing selfdecontaminating novel fibers by fiber spinning, by dipping the conventional textile into the reaction bath possessing nanoparticles, or by coating these nanoparticles onto the textiles substrate. Likewise, among other methods for the application of nanocoating on the textile substrate the sol-gel method is preferred because it can provide the homogenous coating at the molecular level even at lower temperatures along with the large variety of performance.

Titanium sol for the sol-gel process is usually made by any precursors, that is, titanium isopropoxide and titanium chloride. These precursors are used for the formulation of titanium nanoparticles in the presence of water and alcohol in acidic condition by hydrolysis and condensation; later the nanoparticles of titanium are polymerized for the formation 


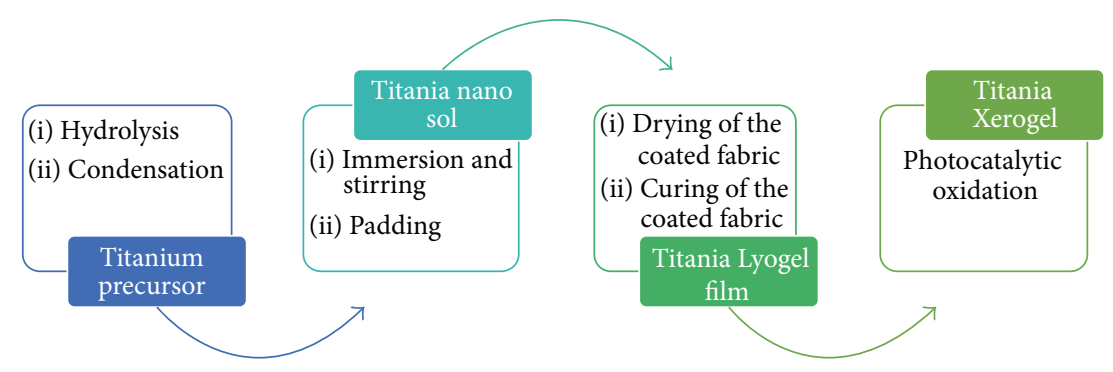

FIGURE 3: Stages of titanium nanoparticles with processes from precursor to coated fabric.

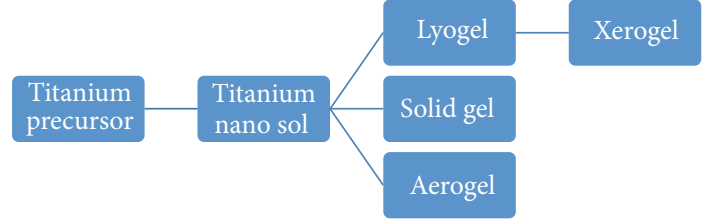

Figure 4: Different forms of titanium nanoparticles based gels at their stages.

of titanium sol. Generally, the fabric is immersed into the titania sol followed by stirring for a certain time or padded under certain pressure for the deposition of titanium nanoparticles on to the surface of the fabric in the Lyogel form. This is followed by drying and curing, which causes the Lyogel to be Xerogel on the coated fabric. The processing stages of titanium nanoparticles from precursor to coated fabric are presented in Figure 3.

The decontamination efficiency of indoor decontamination textile is dependent on the process parameters of the manufacturing of titanium sol including rate of hydrolysis, reaction time and temperature, and amount of precursor, water, and alcohol; that is, the higher rate of hydrolysis leads to the formation of titanium hydroxide rather than polymeric chain of titanium particles, larger reaction time increases diameter of titanium dioxide nanoparticles, larger reaction temperature enhances the rate of coarsening of titanium dioxide nanoparticles, and more amount of precursor at lower hydrolysis rates facilitates the polymerized titanium sol. If the solvent is completely lost and complete polymerization is achieved it would lead to the formation of solid gel. Moreover, if further solvent is removed from the solid gel by supercritical conditions, it would lead to the formation of aerogel. Figure 4 illustrates the different forms of titanium nanoparticles based gels at their stages.

When the nanoparticles are formed by sol-gel method, the nanoparticles are amorphous structures and they are supposed to be converted into crystalline form, which can be done by heating at higher temperature as greater than $400^{\circ} \mathrm{C}$. Yet this higher temperature causes the agglomeration of the nanoparticles due to which surface area and the amount of hydroxyl groups on the surface are reduced. Consequently the photocatalytic activity responsible for the indoor decontamination of the textile material is also decreased. In acidic conditions, the conversion of crystalline structure to amorphous may be achieved at lower than boiling temperature of water. Moreover, amines are also used as surfactants which also perform as the shape controlling agents at highly alkaline $\mathrm{pH}$.

The use of titanium particles onto the polyester fabric is not only limited to indoor decontamination, yet there are various other applications for this fabric. In one research, titanium dioxide nanoparticles on polyester cotton blend have also been applied, and their effects against nerve agent VX have also been studied [16]. In another research, titanium and silver nanoparticle composite has been used to assess the antiodor performance of polyester fabric; the decomposition rate of acetic acid, ammonia gas, and trimethylamine in the presence of UV light was observed to prove its antiodor performance [1]. Titanium dioxide nanoparticles have also been used to modify the dyeability of the polyester fabrics [17].

\section{Mechanism of Decontamination Textiles}

The semiconductors do not conduct electricity mostly, yet when they are brought in contact with energy source or they are excited, they may conduct electricity, so does the titanium. Titanium dioxide is found in three crystalline structures, namely, anatase, rutile, and brookite. Each one requires different energy to be exited, such as when anatase is irradiated with light, whose energy is equal to or greater than its band gap $(388 \mathrm{~nm})$, the negative electrons of the valence band are excited and consequently promoted to the conduction band, leaving positive holes, as presented in Figure 5. The resultant photoinduced negative electrons and positive holes can trigger a series of reduction and oxidation reactions, respectively. The negative electrons react with oxygen molecules, producing superoxide anions $\left(\mathrm{O}_{2}{ }^{-}\right)$, while the positive holes react with water molecules producing hydroxyl radicals $(\mathrm{OH})$.

It should be understood that both the excited electron in the conduction band and generated hole in the valence band should be sufficiently negative and positive, respectively, in order to perform photocatalytic reaction:

$$
\mathrm{TiO}_{2}+h v \longrightarrow \mathrm{h}^{+}+\mathrm{e}^{-}+\mathrm{TiO}_{2}
$$

The ejected electron is excited photoelectron carrying the negative charge $\left(\mathrm{e}^{-}\right)$that is powerful reducing agent, which ionizes the semiconductor $\left(\mathrm{TiO}_{2}, \mathrm{CdS}, \mathrm{ZnO}, \mathrm{ZnS}, \mathrm{Fe}_{2} \mathrm{O}_{3}\right.$, $\mathrm{SnO}_{2}$, etc.), by reduction reaction. The reduction reaction here may be briefly understood as the gain of an electron. 


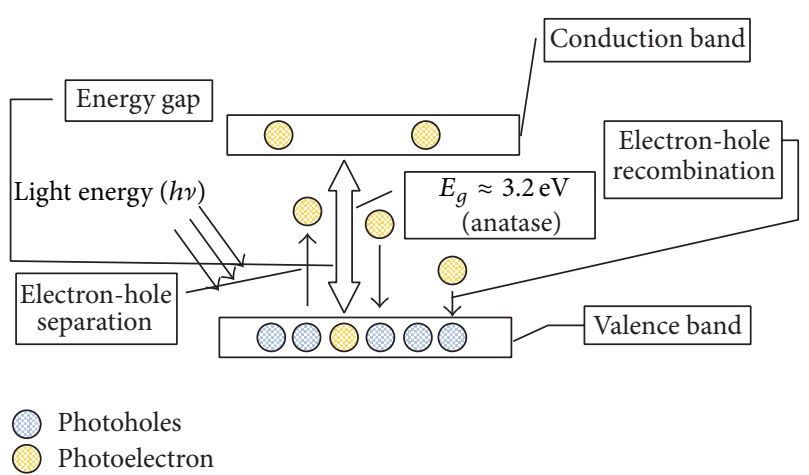

FIGURE 5: Simultaneous electron hole separation and recombination of titanium dioxide (anatase).

Due to electron gain, the positive charge on semiconductor decreases from +4 to +3 :

$$
\mathrm{Ti}^{+4}+\mathrm{e}^{-} \longrightarrow \mathrm{Ti}^{+3}
$$

Later, this reduced semiconductor ionizes and reduces the molecular oxygen $\left(\mathrm{O}_{2}\right)$ present in air of the indoor environment to superoxide $\left(\mathrm{O}_{2}^{-}\right)$:

$$
\mathrm{Ti}^{+3}+\mathrm{O}_{2} \longrightarrow \mathrm{Ti}^{+4}+\mathrm{O}_{2}^{-}
$$

On the other hand, hole generated in the valence band possessing positive charge is highly oxidizing agent, which oxidizes the hydroxyl group $\left(\mathrm{OH}^{-}\right)$of the adsorbed water molecule to free hydroxyl radical $(\mathrm{OH})$ by oxidation reaction:

$$
\mathrm{OH}^{-}+\mathrm{h}^{+} \longrightarrow \mathrm{OH}
$$

Both the superoxide $\left(\mathrm{O}_{2}^{-}\right)$and free hydroxyl radical $(\mathrm{OH})$ are highly reactive and react with the chemical contaminants present in the indoor environment. When the superoxide $\left(\mathrm{O}_{2}{ }^{-}\right)$and free hydroxyl radical $(\mathrm{OH})$ react with pollutants, various harmless products such as $\mathrm{CO}_{2}$ and $\mathrm{H}_{2} \mathrm{O}$ are produced, presented in Figure 6. Thus it confirms the degradation of microorganisms $[18,19]$, inorganic pollutants $[20,21]$, and organic compounds $[19,20]$. The energetics of photo excitation of all three crystalline structures of titanium nanoparticles and how they contribute in different photoexcitation processes are very important to be studied. The band gap increases in the order of rutile $(3.06 \mathrm{eV})$, anatase $(3.2 \mathrm{eV})$, and brookite (3.1 3.4 eV) [22].

\section{Titanium Based Nano Sol Synthesis for Textile Application}

The titanium dioxide nanoparticles have been synthesized by various methods, including nonaqueous sol-gel route at low temperatures [23], microemulsions using hydrothermal method [24, 25], solvothermal method by monodisperse nanoparticles [24, 25], micelle and inverse micelle methods using microemulsions [26], layer by layer method (immersing into two different solutions) [27, 28], layer by layer method (using two sprays) [29], direct oxidation methods at lower temperatures [30], chemical vapor deposition

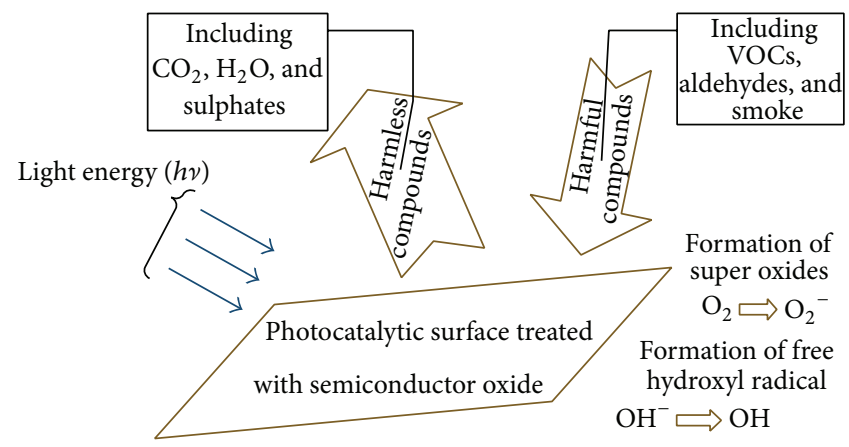

FIGURE 6: Mechanism of decontamination of textiles.

method [31], physical (thermal) vapor deposition method [32], anodic oxidative hydrolysis or electrodeposition method [33], ultrasonic spray pyrolysis (sonochemical method) [34], ultrasonic induced agglomeration [35], and conventional and microwave-hydrothermal deposition methods [36]. The detailed study convening synthesis, properties, and modifications as well as applications of titanium dioxide nonmaterial is already presented [37]; this study focuses on general applications of titanium dioxide nanoparticles rather than particular application on textiles. The sol-gel technology that is an immersing field has been described in detail [38]. Low temperature synthesis of titanium dioxide nanoparticles is the prerequisite for all textile materials; thus mainly research pertaining to textiles relates to sol-gel or hydrothermal method. In both methods, the textile substrate is immersed into the solution followed by drying and curing usually below boiling point of water:

$$
\begin{aligned}
& \text { TBO + Ethanol + Water } \\
& \stackrel{24 \text { hours at } 60^{\circ} \mathrm{C}}{\longrightarrow} \text { Nano Sol } \stackrel{\text { Calcined at } 450^{\circ} \mathrm{C}}{\longrightarrow} \text { Anatase } \\
& \text { TIP + Nitric aci } 900^{\circ} \mathrm{C} \\
& \stackrel{\text { aged for } 1 \text { hour }}{\longrightarrow} \text { Rutile }
\end{aligned}
$$

See [39]. Consider also

TTBO + Nitric acid

$$
\stackrel{40^{\circ} \mathrm{C}-50^{\circ} \mathrm{C}}{\longrightarrow} \text { Nano Sol Rutile (average size of } 50 \mathrm{~nm} \text { ) }
$$

See [40]. Moreover

$$
\mathrm{TTIP}+\frac{\mathrm{HCl}}{\mathrm{HNO}_{3}} \longrightarrow \text { Nano Sol } \frac{<60^{\circ} \mathrm{C} \text { Rutile }}{>60^{\circ} \mathrm{C} \text { Anatase }}
$$

See [41]. Also

$$
\begin{aligned}
& \text { TIP + IPA + Nitric acid + Water } \\
& \longrightarrow \text { Nano Sol } \frac{\text { Rutile (by slow reaction) }}{\text { Anatase (by fast reaction) }}
\end{aligned}
$$

See [42]. 
Usually a small amount of an acid is used in solgel process to be carried out below $100^{\circ} \mathrm{C}$. Titania nano sol is formed by a number of precursors including titanium butoxide (TBO), titanium isopropoxide (TIP), tetratert-butyl orthotitanate (TTBO), titanium tetraisopropoxide (TTIP), as mentioned in (5)-(8). Some researchers have established the methods for the preparation of titanium dioxide nanoparticles at temperatures below $100^{\circ} \mathrm{C}$ in acidic conditions [39-42]. Isopropyl alcohol (IPA) as cosolvent in the synthesis of titanium nanoparticles is also used.

The information about the size and size distribution of titanium nanoparticles is important for controlled photooxidation process, as the size and size distribution directly affect the surface area, which is the most important factor that affects VOCs degradation in catalytic oxidation reactions. The high surface area results in more adsorption sites for pollutants to be oxidized. Therefore, the scientists should synthesize the titanium nanoparticles in such a way so that there would be higher surface area which means smaller particle size and more particle distribution. In addition, there should be more anatase crystalline structure and small amounts of rutile.

\section{5. $\mathrm{TiO}_{2}$ Nanoparticles Settlement on Textile Materials}

The most important part of the research in the area of the application of nanoparticles focuses on the durability of any property, which is dependent upon the binding of nanoparticles to the surface of textile materials. Strong bonding of the nanoparticles with material surfaces not only enhances the life time of property, but also assures resisting of loosely bonded nanoparticles to the environment [43]. In order to achieve strong binding between nanoparticles and fabric, various strategies such as plasma [44], radiofrequency plasma (RF-plasma), microwave plasma (MW-plasma) and vacuumUV [45], RF-plasma and vacuum-UV [46], and plasma jets including arc, spark, and corona [47] have been done as pretreatment of the fabric. Enzymes may also be used to alter the fabric surface properties [48]; and thus they help to impart functionality. Moreover, the colorless, clear, and transparent coatings are wanted, in order to avoid color shifts and changes in hue, tone, or chrome.

Along with the alteration in optical properties, mechanical properties are also important to be considered [49]. In one research, the bending stiffness of the treated and untreated fabric was assessed and it was found that the bending rigidity of the nanocoated fabric was increased by $13 \%$, suggesting that it would not affect adversely the fabric handling [50]. In another research, other mechanical properties, that is, tenacity of nanocoated Lyocell fibers, were assessed after 44 days of exposure to daylight; the chart shown in Figure 7 proves that the pure coating of titanium dioxide nanoparticles changes the mechanical properties significantly, yet they were less affected in the case of $\mathrm{TiO}_{2} \mathrm{P}_{2} 5-\mathrm{SiO}_{2}$ coating [51].

The long lasting of the properties of nanoparticles on the fabric may be assessed by checking the presence of the nanoparticles on the surface of the fabric. This may be achieved by assessing the fabric surface or the existence of the

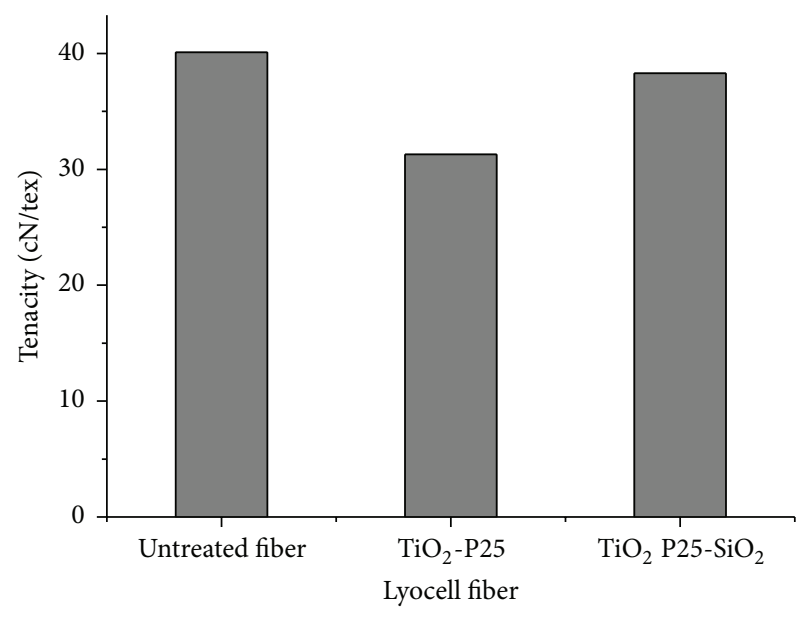

FIgURE 7: Mechanical properties of untreated, $\mathrm{TiO}_{2}$ treated, and $\mathrm{TiO}_{2}-\mathrm{SiO}_{2}$ treated fibers [51].

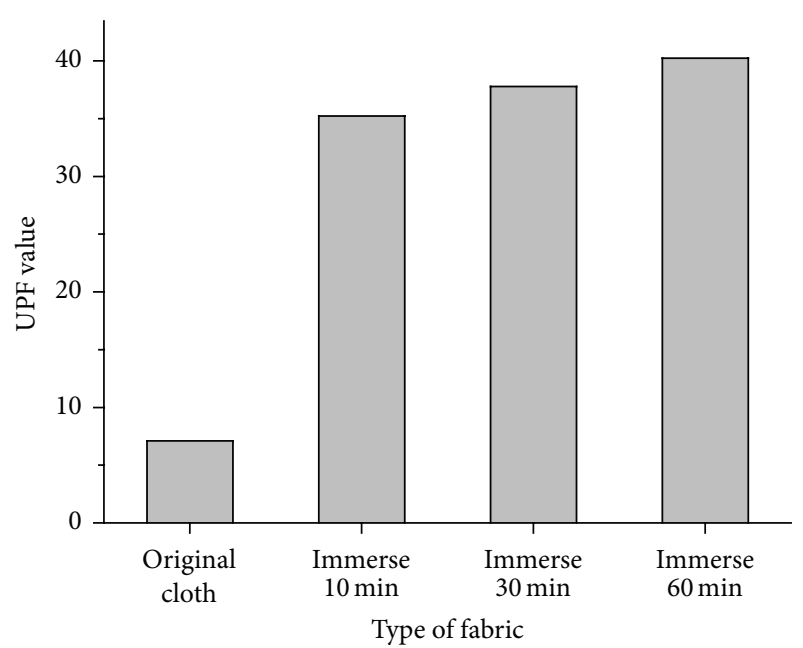

FIGURE 8: UPF values of nanocoated woven polyester fabric at different immersion times [53].

functionality after several numbers of washings. Self-cleaning property of the fabric after 10 and 20 washes was not much different, which confirms that nanoparticles are strongly attached to the fabric surface [52]. In another research, the UPF values were determined for the different immersion times of nanocoated woven polyester fabric [53], as presented in Figure 8.

In some researches, nanoparticles of silicon dioxide have been used as binder between titanium dioxide nanoparticles and the fabric [51, 54, 55]. In another research, the presence of nanoparticles of silicon dioxide resulted in better selfcleaning performance of textile materials [56]. The use of succinic acid [57], succinic acid along with polycarboxylic acids [58], and citric acid [59] as a linking agent between titanium dioxide nanoparticles and fabric has been reported. On the other hand, sol-gel process without any chelating agent has also been reported [60]. The pure protein fibers based fabrics and their blends are being used in different applications [61]. The binding of the cations of $\mathrm{Cu}(\mathrm{II})$ and 


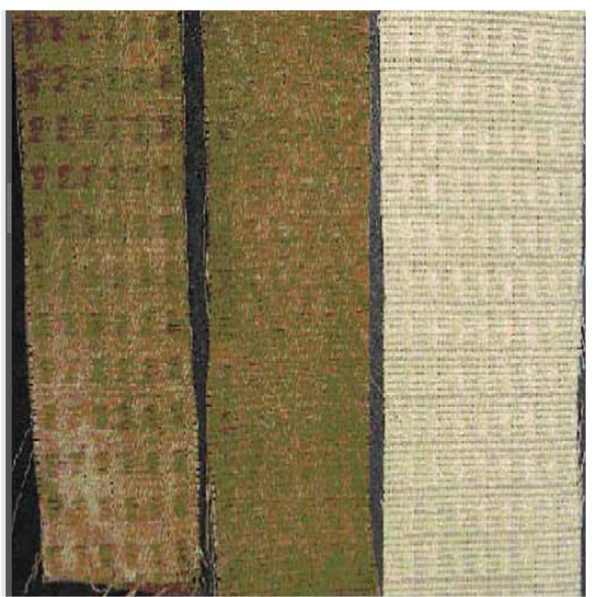

(a)

(b)

(c)

FIGURE 9: Antidust performance of polyester fabric. (a) Titanium dioxide coated fabric after flow of dust, (b) uncoated fabric after flow of dust, and (c) initial fabric before flow of dust [45].

$\mathrm{Co}$ (II) on wool fiber has been studied [62]. Alginate with $\mathrm{Ca}+$ ions [63] and zinc has been reported [64]. Iron nanoparticles as photocatalyst have been assessed to compare their performance with titanium nanoparticles [65].

The pure polyester does not have stronger affinity towards nanoparticles; thus it needs any further modification in order to get maximum bonding. In one research, lipase treatment has been done on the polyester [66]. Similarly, in one research, enzymatic hydrolysis was used to alter the properties of polyester [67]. In another research, alginate was used in order to apply titanium dioxide nanoparticles on polyester fabrics; the consequential better properties were achieved [68]. Titanium dioxide on polyester/wool blends was applied after the application of protease-Savinase and lipase-Lipex enzymes [69]; the same enzyme, that is, protease, has been used to impart functionality to wool [70]. Lipase is used to functionalize polyesters since it has the ability to hydrolyze carboxylic esters $[48,66,67]$. The synthesis of nanoparticles and hydrolysis of the polyester fabric surface simultaneously has been done by in situ synthesis [71]. In this method, titanium nanoparticles and silver precursor were added to the alkaline bath made by sodium hydroxide and polyester fabric at boiling temperature for an hour [71].

Polyester fabric has been pretreated by radiofrequency plasma (RF-plasma); microwave plasma (MW-plasma); and vacuum-UV followed by coating with titanium dioxide nanoparticles, and its antidust performance has been assessed. Figure 9 shows the antidust performance of polyester fabric that was pretreated with RF-plasma for 30 min and later coated with $\mathrm{TiO}_{2}$ [45].

Plasma pretreatment for enhancing the photocatalytic efficiency and binding strength [72] and low plasma pretreatment to enhance binding strength between nanoparticles and the surface of polyester [73] and polyester and other fabrics [72] have before nanocoating with titanium dioxide been suggested. Polyester has carboxylic groups in its structure; thus alginate can be used in its surface modification; a layer of nanoparticles by hydrothermal method on the polyester fabric offering better anti-UV and photodegradation of dye proved the significance of applied nanocoating [74].

\section{Health Issues Related to Photocatalytic Oxidation and Nanoparticles}

In the last decade, the environmental hazards related to pesticides and biocides were pronounced. This was followed by genetically modifying strategies, hybrid foods, eco-friendly dyeing [75], and desalination of water. It is a time when nanoparticles are at the peak to be concerned about. There is a lot of research being done in the area of nanomaterials, for example, green synthesis of silver nanoparticles [76]; it suggests doing careful investigation of its consequences on the health, as most of the materials that are used may offer poor wash fastness properties. This will lead to the environmental problems; although a lot of research is being done to assure better fastness, yet there is a lot to be researched more. Photocatalytic oxidation which generates superoxide $\left(\mathrm{O}_{2}{ }^{-}\right)$ and hydroxide radical $(\mathrm{OH})$ could be harmful for human physiological system. How to reduce the harmful effect on human health by keeping its usual microbial activities may be worthy of research in this context.

In a recent study, the use of silica and titanium dioxide $\left(\mathrm{TiO}_{2}\right)$ nanoparticles has been reported to have led to pregnancy complications in mice and neurotoxicity in their offspring [77]. It was found that nano- $\mathrm{TiO}_{2}$ and $\mathrm{nSP} 70$ injected into pregnant mice were then observed in the placenta, fetal liver, and fetal brain leading to growth implications of the fetus. In another study, for the first time, the effect of nanoparticles on the human beings was mentioned; it was maintained that inhalation of nanoparticles for half to one year caused severe lung damage; this finding makes nanoscientists pondered regarding environmental and health concerns of nanoparticles [78]. Panagopoulos et al. [2] investigated several cases of nanoparticle inhalation in humans that led to lung damage. The patients had been exposed to chemicals synthesized with various nanoparticles, such as titanium dioxide and thin zinc oxide, leading to severe pleural effusions and pulmonary fibrosis. The report details that the exposure of polyacrylic ester without proper protection can lead to pulmonary difficulties as well as accumulation of nanoparticles within the cytoplasm of the pulmonary epithelial layer leading to disruption monocyte function.

It has been reported that nanoparticles can cause indirect DNA damage in vitro across trophoblast and corneal barriers and cause cytokine and chemokine release across corneal barriers [79]. By using secondary messengers such as ATP (adenosine triphosphate) and $\mathrm{Ca} 2+$, nanoparticles can induce production of ROS (radical oxygen species) which can damage mRNA gene expression in cells with bilayered/multilayered barriers. In another study, the consequences of cobalt-chromium nanoparticles on the damage of DNA across a cellular barrier have been described [80]. The nanoparticles did not pass through the barrier; instead the damage was mediated by a novel mechanism involving pannexin and connexin hemichannels and gap junctions and 
purinergic signaling. These are a few observations, which have been reported by scientists in the short period of extensive research over nanoparticles, yet there could be many other issues that have not been brought into consideration. It is important for urgent evaluation of nanoparticles and their risk to human health, particularly in cosmetic and industrial areas where stronger metals such as titanium oxide are in regular use.

\section{Conclusion}

It may be summed up that dwellings where one spends most of his time are full of sources that cause air pollution; and thus carrying out the remedy of this problem is highly needed. On the other hand, these dwellings are also full of textile materials; thus photocatalytic oxidation applied on the textile materials is better solution of this problem. The photocatalytic oxidation requires a semiconductor as it allows the movement of electrons from the valence band to the conduction band when it is excited. Among other various semiconductors, titanium dioxide is researched and studied mostly due to its numerous advantages over other semiconductors. Titanium dioxide is reduced by electron in its valence band leading to the reduction of molecular oxygen in the environment; meanwhile, hydroxyl group is capable of oxidizing water molecule. As a result photocatalytic oxidation takes place.

Among other methods of synthesis of titanium dioxide, sol-gel method is preferred due to its benefits over other methods. Various precursors have been used for the synthesis of nanoparticles to form the titania nano sol. Along with the application in the area of indoor decontamination, there are other numerous properties that have been assessed for titanium dioxide nanoparticles. Even today, the deposition of these nanoparticles on the textile substrate is state of the art, yet various researches have been made to enhance the fastness properties of the nanocoated textile materials. There are several medical issues being raised by time and suggest the strong need to answer all the stated problems.

\section{Conflict of Interests}

The authors declare that there is no conflict of interests.

\section{Acknowledgment}

The authors are thankful to Professor Zhu Chengyan for providing his guidance.

\section{References}

[1] C.-C. Chen, C.-C. Wang, and J.-T. Yeh, "Improvement of odor elimination and anti-bacterial activity of polyester fabrics finished with composite emulsions of nanometer titanium dioxide-silver particles-water-borne polyurethane," Textile Research Journal, vol. 80, no. 4, pp. 291-300, 2010.

[2] I. K. Panagopoulos, A. N. Karayannis, P. Kassomenos, and K. Aravossis, "A CFD simulation study of VOC and formaldehyde indoor air pollution dispersion in an apartment as part of an indoor pollution management plan," Aerosol and Air Quality Research, vol. 11, no. 6, pp. 758-762, 2011.

[3] E. Barrese, A. Gioffrè, M. Scarpelli, D. Turbante, R. Trovato, and S. Iavicoli, "Indoor pollution in work office: VOCs, formaldehyde and ozone by printer," Occupational Diseases and Environmental Medicine, vol. 2, pp. 49-55, 2014.

[4] G. D. J. Huezhi, "Indoor air pollution caused by decorative materials," Shanghai Environmental Sciences, vol. 13, article 3, 1994.

[5] M. Hippelein, "Background concentrations of individual and total volatile organic compounds in residential indoor air of Schleswig-Holstein, Germany," Journal of Environmental Monitoring, vol. 6, no. 9, pp. 745-752, 2004.

[6] D. R. Crump, R. W. Squire, and C. W. F. Yu, "Sources and concentrations of formaldehyde and other volatile organic compounds in the indoor air of four newly built unoccupied test houses," Indoor and Built Environment, vol. 6, no. 1, pp. 4555, 1997.

[7] J. M. Daisey, A. T. Hodgson, W. J. Fisk, M. J. Mendell, and J. Ten Brinke, "Volatile organic compounds in twelve California office buildings: classes, concentrations and sources," Atmospheric Environment, vol. 28, no. 22, pp. 3557-3562, 1994.

[8] Y. Chun-Guang, L. Xue-Yuan, X. Qi-Quan, and S. Zhong-You, "Temperature control and surface cooler reform in operating room air decontamination system," Chinese Medical Equipment Journal, vol. 30, 2009.

[9] C. C. Wu, G. W. M. Lee, S. Yang, K.-P. Yu, and C. L. Lou, "Influence of air humidity and the distance from the source on negative air ion concentration in indoor air," Science of the Total Environment, vol. 370, no. 1, pp. 245-253, 2006.

[10] D. L. MacIntosh, T. Minegishi, M. Kaufman et al., “The benefits of whole-house in-duct air cleaning in reducing exposures to fine particulate matter of outdoor origin: a modeling analysis," Journal of Exposure Science and Environmental Epidemiology, vol. 20, no. 2, pp. 213-224, 2010.

[11] A. L. Hill, "Method and apparatus for decontaminating a region without dehumidification," 2011.

[12] E. M. Surdo, I. A. Khan, A. A. Choudhury, N. B. Saleh, and W. A. Arnold, "Barrier properties of poly(vinyl alcohol) membranes containing carbon nanotubes or activated carbon," Journal of Hazardous Materials, vol. 188, no. 1-3, pp. 334-340, 2011.

[13] T. J. Mielnik, E. W. Krieger, D. L. Eddington, and G. C. Koos, "Room decontamination with hydrogen peroxide vapor," US 20060008379 Al, 2008.

[14] Z. Grabarczyk, "Effectiveness of indoor air cleaning with corona ionizers," Journal of Electrostatics, vol. 51-52, no. 1-4, pp. 278283, 2001.

[15] K. Omasa, K. Tobe, and T. Kondo, "Absorption of organic and inorganic air pollutants by plants," in Air Pollution and Plant Biotechnology, K. Omasa, H. Saji, S. Youssefian, and N. Kondo, Eds., pp. 155-178, Springer, Tokyo, Japan, 2002.

[16] Ž. Senić, S. Bauk, D. Simić et al., "The preliminary comparative analysis of different routes for $\mathrm{TiO}_{2}$ nanoparticles synthesis and their deposition on textiles. The methyl-orange degradation and VX detoxication study," Digest Journal of Nanomaterials and Biostructures, vol. 8, no. 2, pp. 711-719, 2013.

[17] T. Harifi and M. Montazer, "Free carrier dyeing of polyester fabric using nano $\mathrm{TiO}_{2}$," Dyes and Pigments, vol. 97, no. 3, pp. 440-445, 2013.

[18] Y. Kikuchi, K. Sunada, T. Iyoda, K. Hashimoto, and A. Fujishima, "Photocatalytic bactericidal effect of $\mathrm{TiO}_{2}$ thin films: 
dynamic view of the active oxygen species responsible for the effect," Journal of Photochemistry and Photobiology A: Chemistry, vol. 106, no. 1-3, pp. 51-56, 1997.

[19] A. G. Agrios and P. Pichat, "State of the art and perspectives on materials and applications of photocatalysis over $\mathrm{TiO}_{2}$," Journal of Applied Electrochemistry, vol. 35, no. 7-8, pp. 655-663, 2005.

[20] K. Demeestere, J. Dewulf, and H. Van Langenhove, "Heterogeneous photocatalysis as an advanced oxidation process for the abatement of chlorinated, monocyclic aromatic and sulfurous volatile organic compounds in air: state of the art," Critical Reviews in Environmental Science and Technology, vol. 37, no. 6, pp. 489-538, 2007.

[21] F. L. Toma, G. Bertrand, D. Klein, and C. Coddet, "Photocatalytic removal of nitrogen oxides via titanium dioxide," Environmental Chemistry Letters, vol. 2, no. 3, pp. 117-121, 2004.

[22] D. Reyes-Coronado, G. Rodríguez-Gattorno, M. E. EspinosaPesqueira, C. Cab, R. de Coss, and G. Oskam, "Phase-pure $\mathrm{TiO}_{2}$ nanoparticles: anatase, brookite and rutile," Nanotechnology, vol. 19, no. 14, Article ID 145605, 2008.

[23] M. Niederberger, M. H. Bartl, and G. D. Stucky, "Benzyl alcohol and titanium tetrachloride-a versatile reaction system for the nonaqueous and low-temperature preparation of crystalline and luminescent titania nanoparticles," Chemistry of Materials, vol. 14, no. 10, pp. 4364-4370, 2002.

[24] M. Andersson, L. Österlund, S. Ljungström, and A. Palmqvist, "Preparation of nanosize anatase and rutile $\mathrm{TiO}_{2}$ by hydrothermal treatment of microemulsions and their activity for photocatalytic wet oxidation of phenol," Journal of Physical Chemistry $B$, vol. 106, no. 41, pp. 10674-10679, 2002.

[25] X.-L. Li, Q. Peng, J.-X. Yi, X. Wang, and Y. Li, "Near monodisperse $\mathrm{TiO}_{2}$ nanoparticles and nanorods," Chemistry - A European Journal, vol. 12, no. 8, pp. 2383-2391, 2006.

[26] S.-S. Hong, M. S. Lee, S. S. Park, and G.-D. Lee, "Synthesis of nanosized $\mathrm{TiO}_{2} / \mathrm{SiO}_{2}$ particles in the microemulsion and their photocatalytic activity on the decomposition of p-nitrophenol," Catalysis Today, vol. 87, no. 1-4, pp. 99-105, 2003.

[27] M. Grandcolas, L. Sinault, F. Mosset, A. Louvet, N. Keller, and V. Keller, "Self-decontaminating layer-by-layer functionalized textiles based on $\mathrm{WO}_{3}$-modified titanate nanotubes. Application to the solar photocatalytic removal of chemical warfare agents," Applied Catalysis A: General, vol. 391, no. 1-2, pp. 455-467, 2011.

[28] M. Grandcolas, A. Louvet, N. Keller, and V. Keller, "Layerby-layer deposited titanate-based nanotubes for solar photocatalytic removal of chemical warfare agents from textiles," Angewandte Chemie-International Edition, vol. 48, no. 1, pp. 161-164, 2009.

[29] K. C. Krogman, N. S. Zacharia, D. M. Grillo, and P. T. Hammond, "Photocatalytic layer-by-layer coatings for degradation of acutely toxic agents," Chemistry of Materials, vol. 20, no. 5, pp. 1924-1930, 2008.

[30] J.-M. Wu, "Low-temperature preparation of titania nanorods through direct oxidation of titanium with hydrogen peroxide," Journal of Crystal Growth, vol. 269, no. 2-4, pp. 347-355, 2004.

[31] S. Seifried, M. Winterer, and H. Hahn, "Nanocrystalline titania films and particles by chemical vapor synthesis," Chemical Vapor Deposition, vol. 6, no. 5, pp. 239-244, 2000.

[32] J.-M. Wu, H. C. Shih, and W.-T. Wu, "Electron field emission from single crystalline $\mathrm{TiO}_{2}$ nanowires prepared by thermal evaporation," Chemical Physics Letters, vol. 413, no. 4-6, pp. 490-494, 2005.

[33] Y. Lei, L. D. Zhang, and J. C. Fan, "Fabrication, characterization and Raman study of $\mathrm{TiO}_{2}$ nanowire arrays prepared by anodic oxidative hydrolysis of $\mathrm{TiCl}_{3}$," Chemical Physics Letters, vol. 338, no. 4-6, pp. 231-236, 2001.

[34] M. D. Blešić, Z. V. Šaponjić, J. M. Nedeljković, and D. P. Uskoković, " $\mathrm{TiO}_{2}$ films prepared by ultrasonic spray pyrolysis of nanosize precursor," Materials Letters, vol. 54, no. 4, pp. 298302, 2002.

[35] J. C. Yu, L. Zhang, and J. Yu, "Rapid synthesis of mesoporous $\mathrm{TiO}_{2}$ with high photocatalytic activity by ultrasound-induced agglomeration," New Journal of Chemistry, vol. 26, no. 4, pp. $416-420,2002$.

[36] A. B. Corradi, F. Bondioli, B. Focher et al., "Conventional and microwave-hydrothermal synthesis of $\mathrm{TiO}_{2}$ nanopowders," Journal of the American Ceramic Society, vol. 88, no. 9, pp. 26392641, 2005.

[37] X. Chen and S. S. Mao, "Titanium dioxide nanomaterials: synthesis, properties, modifications, and applications," Chemical Reviews, vol. 107, no. 7, pp. 2891-2959, 2007.

[38] C. J. Brinker and G. W. Scherer, Sol-Gel Science: The Physics and Chemistry of Sol-Gel Processing, Academic Press, Boston, Mass, USA, 1990.

[39] S. Watson, D. Beydoun, J. Scott, and R. Amal, "Preparation of nanosized crystalline $\mathrm{TiO}_{2}$ particles at low temperature for photocatalysis," Journal of Nanoparticle Research, vol. 6, pp. 193$207,2004$.

[40] Z. Tang, J. Zhang, Z. Cheng, and Z. Zhang, "Synthesis of nanosized rutile $\mathrm{TiO}_{2}$ powder at low temperature," Materials Chemistry and Physics, vol. 77, no. 2, pp. 314-317, 2003.

[41] S. Yin, R. Li, Q. He, and T. Sato, "Low temperature synthesis of nanosize rutile titania crystal in liquid media," Materials Chemistry and Physics, vol. 75, no. 1-3, pp. 76-80, 2002.

[42] M. Gopal, W. J. M. Chan, and L. C. De Jonghe, "Room temperature synthesis of crystalline metal oxides," Journal of Materials Science, vol. 32, no. 22, pp. 6001-6008, 1997.

[43] S. Gowri, L. Almeida, T. Amorim, N. Carneiro, A. P. Souto, and M. F. Esteves, "Polymer nanocomposites for multifunctional finishing of textiles-a review," Textile Research Journal, vol. 80, no. 13, pp. 1290-1306, 2010.

[44] C.-M. Chan, T.-M. Ko, and H. Hiraoka, "Polymer surface modification by plasmas and photons," Surface Science Reports, vol. 24, no. 1-2, pp. 1-54, 1996.

[45] A. Bozzi, T. Yuranova, and J. Kiwi, "Self-cleaning of woolpolyamide and polyester textiles by $\mathrm{TiO}_{2}$-rutile modification under daylight irradiation at ambient temperature," Journal of Photochemistry and Photobiology A: Chemistry, vol. 172, no. 1, pp. 27-34, 2005.

[46] T. Yuranova, A. G. Rincon, A. Bozzi et al., "Antibacterial textiles prepared by RF-plasma and vacuum-UV mediated deposition of silver," Journal of Photochemistry and Photobiology A: Chemistry, vol. 161, no. 1, pp. 27-34, 2003.

[47] J. F. Friedrich, P. Rohrer, W. Saur, T. Gross, A. Lippitz, and W. Unger, "Improvement in polymer adhesivity by low and normal pressure plasma surface modification," Surface and Coatings Technology, vol. 59, no. 1-3, pp. 371-378, 1993.

[48] J. Shen, M. Rushforth, A. Cavaco-Paulo, G. Guebitz, and H. Lenting, "Development and industrialisation of enzymatic shrink-resist process based on modified proteases for wool machine washability," Enzyme and Microbial Technology, vol. 40, no. 7, pp. 1656-1661, 2007.

[49] H. Memon, "Effect of a Biodegradable salts (Sodium NTA and tetrasodium EDTA) on the mechanical properties of the fabric," in Proceedings of the Student Research Paper Conference, M.U.E.T., Jamshoro, Pakistan, 2012. 
[50] K. Qi, X. Wang, and J. H. Xin, "Photocatalytic self-cleaning textiles based on nanocrystalline titanium dioxide," Textile Research Journal, vol. 81, no. 1, pp. 101-110, 2011.

[51] N. Veronovski, M. Sfiligoj-Smole, and J. L. Viota, "Characterization of $\mathrm{TiO}_{2} / \mathrm{TiO}_{2}-\mathrm{SiO}_{2}$ coated cellulose textiles," Textile Research Journal, vol. 80, no. 1, pp. 55-62, 2010.

[52] W. A. Daoud and J. H. Xin, "Low temperature sol-gel processed photocatalytic titania coating," Journal of Sol-Gel Science and Technology, vol. 29, no. 1, pp. 25-29, 2004.

[53] H. Memon, W. Ningning, W. Puying, W. Quan, W. Jue, and Z. Chengyan, "Wrinkle resistance and anti UV by nanocoating, with no change in visual appearance," in Proceedings of the 6th International Color \& Coating Congress (ICCC '15), Tehran, Iran, November 2015.

[54] T. Yuranova, R. Mosteo, J. Bandara, D. Laub, and J. Kiwi, "Self-cleaning cotton textiles surfaces modified by photoactive $\mathrm{SiO}_{2} / \mathrm{TiO}_{2}$ coating," Journal of Molecular Catalysis A: Chemical, vol. 244, no. 1-2, pp. 160-167, 2006.

[55] M. I. Mejía, J. M. Marín, G. Restrepo, L. A. Rios, C. Pulgarín, and J. Kiwi, "Preparation, testing and performance of a $\mathrm{TiO}_{2}$ /polyester photocatalyst for the degradation of gaseous methanol," Applied Catalysis B: Environmental, vol. 94, no. 1-2, pp. 166-172, 2010.

[56] K. Qi, X. Chen, Y. Liu, J. H. Xin, C. L. Mak, and W. A. Daoud, "Facile preparation of anatase $/ \mathrm{SiO}_{2}$ spherical nanocomposites and their application in self-cleaning textiles," Journal of Materials Chemistry, vol. 17, no. 33, pp. 3504-3508, 2007.

[57] K. T. Meilert, D. Laub, and J. Kiwi, "Photocatalytic selfcleaning of modified cotton textiles by $\mathrm{TiO}_{2}$ clusters attached by chemical spacers," Journal of Molecular Catalysis A: Chemical, vol. 237, no. 1-2, pp. 101-108, 2005.

[58] A. Steinbüchel, M. Hofrichter, and S. R. Fahnestock, Polyamides and Complex Proteinaceous Materials II, vol. 8, Wiley-Blackwell, 2003.

[59] A. A. Okeil, "Citric acid crosslinking of cellulose using $\mathrm{TiO}_{2}$ catalyst by pad-dry-cure method," Polymer-Plastics Technology and Engineering, vol. 47, no. 2, pp. 174-179, 2008.

[60] R. Campostrini, M. Ischia, and L. Palmisano, "Pyrolysis study of sol-gel derived $\mathrm{TiO}_{2}$ powders: part IV. $\mathrm{TiO}_{2}$-anatase prepared by hydrolysing titanium(IV) isopropoxide without chelating agents," Journal of Thermal Analysis and Calorimetry, vol. 75, no. 1, pp. 25-34, 2004.

[61] M. Lewin, Handbook of Fiber Chemistry, CRC Press, 3rd edition, 2006.

[62] P. Taddei, P. Monti, G. Freddi, T. Arai, and M. Tsukada, "Binding of $\mathrm{Co}(\mathrm{II})$ and $\mathrm{Cu}(\mathrm{II})$ cations to chemically modified wool fibres: an IR investigation," Journal of Molecular Structure, vol. 650, no. 1-3, pp. 105-113, 2003.

[63] M. A. D. Silva, A. C. K. Bierhalz, and T. G. Kieckbusch, "Alginate and pectin composite films crosslinked with $\mathrm{Ca}^{2}+$ ions: Effect of the plasticizer concentration," Carbohydrate Polymers, vol. 77, no. 4, pp. 736-742, 2009.

[64] M. Gorenšek and V. Bukošek, "Zinc and alginate for multipurpose textiles," Acta Chimica Slovenica, vol. 53, no. 2, pp. 223-228, 2006.

[65] M. R. Dhananjeyan, E. Mielczarski, K. R. Thampi et al., "Photodynamics and surface characterization of $\mathrm{TiO}_{2}$ and $\mathrm{Fe}_{2} \mathrm{O}_{3}$ photocatalysts immobilized on modified polyethylene films," The Journal of Physical Chemistry B, vol. 105, no. 48, pp. 1204612055, 2001.

[66] H. R. Kim and W. S. Song, "Lipase treatment of polyester fabrics," Fibers and Polymers, vol. 7, no. 4, pp. 339-343, 2006.
[67] Y.-L. Hsieh and L. A. Cram, "Enzymatic hydrolysis to improve wetting and absorbency of polyester fabrics," Textile Research Journal, vol. 68, no. 5, pp. 311-319, 1998.

[68] D. Mihailović, Z. Šaponjić, M. Radoičić et al., "Functionalization of polyester fabrics with alginates and $\mathrm{TiO}_{2}$ nanoparticles," Carbohydrate Polymers, vol. 79, no. 3, pp. 526-532, 2010.

[69] M. Montazer and S. Seifollahzadeh, "Enhanced self-cleaning, antibacterial and UV protection properties of nano $\mathrm{TiO}_{2}$ treated textile through enzymatic pretreatment," Photochemistry and Photobiology, vol. 87, no. 4, pp. 877-883, 2011.

[70] K. Schumacher, E. Heine, and H. Höcker, "Extremozymes for improving wool properties," Journal of Biotechnology, vol. 89, no. 2-3, pp. 281-288, 2001.

[71] V. Allahyarzadeh, M. Montazer, N. H. Nejad, and N. Samadi, "In situ synthesis of nano silver on polyester using $\mathrm{NaOH} / \mathrm{Nano}$ $\mathrm{TiO}_{2}$," Journal of Applied Polymer Science, vol. 129, no. 2, pp. 892-900, 2013.

[72] T. Yuranova, D. Laub, and J. Kiwi, "Synthesis, activity and characterization of textiles showing self-cleaning activity under daylight irradiation," Catalysis Today, vol. 122, no. 1-2, pp. 109117, 2007.

[73] K. Qi, J. H. Xin, W. A. Daoud, and C. L. Mak, "Functionalizing polyester fiber with a self-cleaning property using anatase $\mathrm{TiO}_{2}$ and low-temperature plasma treatment," International Journal of Applied Ceramic Technology, vol. 4, no. 6, pp. 554-563, 2007.

[74] H. Zhang, H. Zhu, and R. Sun, "Fabrication of photocatalytic $\mathrm{TiO}_{2}$ nanoparticle film on pet fabric by hydrothermal method," Textile Research Journal, vol. 82, no. 8, pp. 747-754, 2012.

[75] A. Khatri, H. Memon, S. Qureshi, F. Zaib, and A. Khatri, "Effluent pollution by using trisodium nitrilotriacetate in batch process of dyeing cotton fabric with fiber-reactive dyes," in Proceedings of the International Colloquium in Textile Engineering, Fashion, Apparel and Design 2014 (ICTEFAD 2014), pp. 107-111, Springer, Singapore, 2014.

[76] Y. Liu, M. Hussain, H. Memon, and S. Yasin, "Solar irradiation and Nageia nagi extract assisted rapid synthesis of silver nanoparticles and their antibacterial activity," Digest Journal of Nanomaterials and Biostructures, vol. 10, no. 3, pp. 1019-1024, 2015.

[77] K. Yamashita, Y. Yoshioka, K. Higashisaka et al., "Silica and titanium dioxide nanoparticles cause pregnancy complications in mice," Nature Nanotechnology, vol. 6, no. 5, pp. 321-328, 2011.

[78] Y. Song, X. Li, and X. Du, "Exposure to nanoparticles is related to pleural effusion, pulmonary fibrosis and granuloma," European Respiratory Journal, vol. 34, no. 3, pp. 559-567, 2009.

[79] A. Sood, S. Salih, D. Roh et al., "Signalling of DNA damage and cytokines across cell barriers exposed to nanoparticles depends on barrier thickness," Nature Nanotechnology, vol. 6, no. 12, pp. 824-833, 2011.

[80] G. Bhabra, A. Sood, B. Fisher et al., "Nanoparticles can cause DNA damage across a cellular barrier," Nature Nanotechnology, vol. 4, no. 12, pp. 876-883, 2009. 

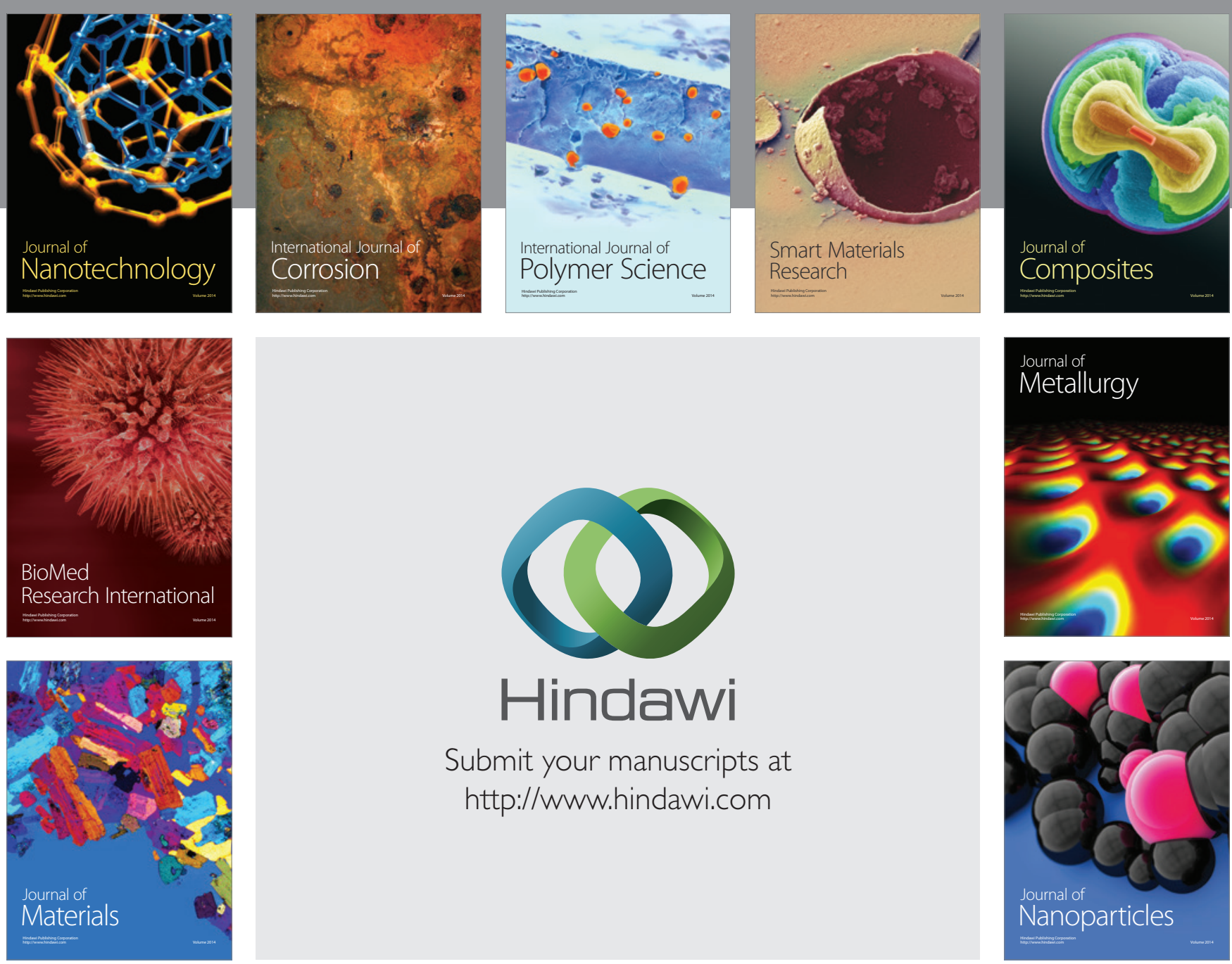

Submit your manuscripts at http://www.hindawi.com
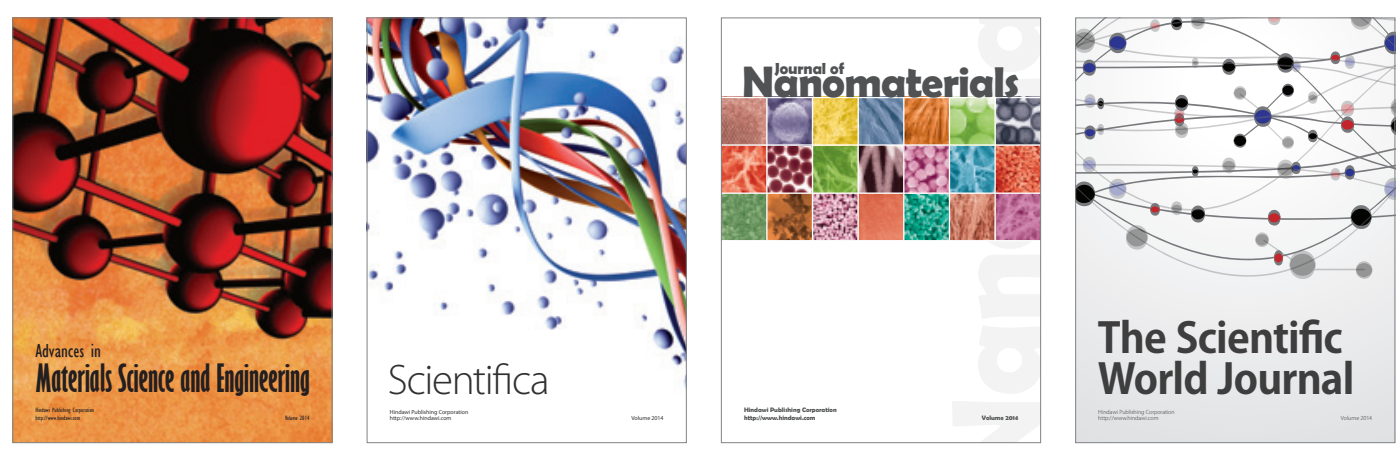

\section{The Scientific World Journal}
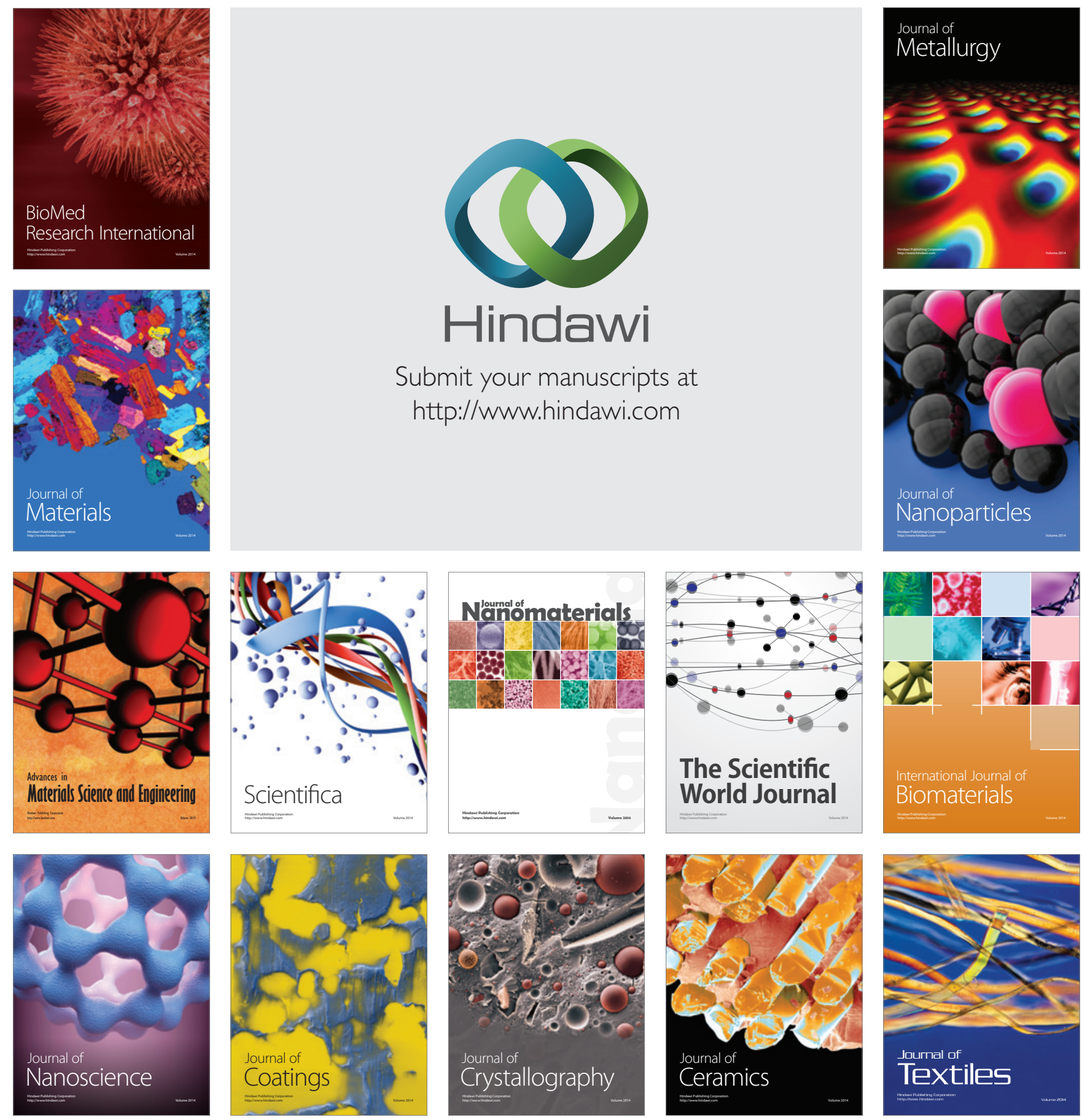